\title{
Use of medical face masks versus particulate respirators as a component of personal protective equipment for health care workers in the context of the COVID-19 pandemic
}

\author{
John Conly ${ }^{1 *}$ D, W. H. Seto ${ }^{2}$, Didier Pittet ${ }^{3}$, Alison Holmes ${ }^{4}$, May Chu ${ }^{5}$, Paul R. Hunter ${ }^{6}$, on behalf of the WHO
} Infection Prevention and Control Research and Development Expert Group for COVID-19

\begin{abstract}
Currently available evidence supports that the predominant route of human-to-human transmission of the SARS$\mathrm{CoV}-2$ is through respiratory droplets and/or contact routes. The report by the World Health Organization (WHO) Joint Mission on Coronavirus Disease 2019 (COVID-19) in China supports person-to-person droplet and fomite transmission during close unprotected contact with the vast majority of the investigated infection clusters occurring within families, with a household secondary attack rate varying between 3 and 10\%, a finding that is not consistent with airborne transmission. The reproduction number $\left(\mathrm{R}_{0}\right)$ for the SARS-CoV-2 is estimated to be between 2.2-2.7, compatible with other respiratory viruses associated with a droplet/contact mode of transmission and very different than an airborne virus like measles with a $R_{0}$ widely cited to be between 12 and 18 . Based on the scientific evidence accumulated to date, our view is that SARS-CoV-2 is not spread by the airborne route to any significant extent and the use of particulate respirators offers no advantage over medical masks as a component of personal protective equipment for the routine care of patients with COVID-19 in the health care setting. Moreover, prolonged use of particulate respirators may result in unintended harms. In conjunction with appropriate hand hygiene, personal protective equipment (PPE) used by health care workers caring for patients with COVID-19 must be used with attention to detail and precision of execution to prevent lapses in adherence and active failures in the donning and doffing of the PPE.
\end{abstract}

Keywords: SARS-CoV-2, COVID-19, Droplet, Contact, Airborne, Infection prevention, Transmission, Medical mask, N95 respirator

\footnotetext{
* Correspondence: jconly@ucalgary.ca

${ }^{1}$ University of Calgary and Alberta Health Services, Calgary, Alberta, Canada

Full list of author information is available at the end of the article
} 4.0 International License, which permits use, sharing, adaptation, distribution and reproduction in any medium or format, as long as you give appropriate credit to the original author(s) and the source, provide a link to the Creative Commons licence, and indicate if changes were made. The images or other third party material in this article are included in the article's Creative Commons licence, unless indicated otherwise in a credit line to the material. If material is not included in the article's Creative Commons licence and your intended use is not permitted by statutory regulation or exceeds the permitted use, you will need to obtain permission directly from the copyright holder. To view a copy of this licence, visit http://creativecommons.org/ licenses/by/4.0/. The Creative Commons Public Domain Dedication waiver (http://creativecommons.org/publicdomain/zero/1. 0/) applies to the data made available in this article, unless otherwise stated in a credit line to the data. 


\section{Background}

The mechanisms of transmission (airborne, droplet, contact, vector or common vehicle) for microorganisms supports a specific combination of barrier precautions chosen on the basis of a point-of-care risk assessment by the health care worker $(\mathrm{HCW})[1,2]$. Any person who is in close contact (generally considered to be within $1 \mathrm{~m}$ ) with someone who has respiratory symptoms (e.g., sneezing or coughing) is at risk of being exposed to potentially infective respiratory droplets. Moreover, droplet transmission may also produce fomites on any surface in the immediate environment around the infected person. Airborne transmission refers to the presence of microbes within droplet nuclei (generally considered to be particles $<5-10 \mu \mathrm{m}$ in diameter), which result from the evaporation of larger droplets and/or exist within dust particles and may remain in the air for long periods of time and may be transmitted to others over longer distances such as the measles virus [2-4]. However, it is important to recognize that in the course of medical care, aerosols of particles generally considered to be $<5-10 \mu \mathrm{m}$ may be generated in certain procedures considered to be "aerosol-generating medical procedures" (AGMP) and transmitted at limited distances beyond 1 $\mathrm{m}$, which has been referred to as "opportunistic" airborne transmission and airborne precautions are appropriate for these settings [4]. Within the context of the general understanding of the routes of droplet and opportunistic airborne transmission, controversy exists about the relative contribution and importance of the routes of each of them related to specific viruses. For example a systematic review of the literature concluded that influenza virus transmission in humans occurs only over short distances consistent with predominantly the droplet route [5], but Tellier suggested that limited aerosol transmission over longer distances can occur in addition to droplet transmission $[6,7]$. It is recognized that there is a continuum of transmission routes between large droplet and aerosol and it is an important concept. Particles of a variety of sizes are expelled from the human airway during coughing, sneezing, talking and medical procedures.

The aerobiology of expired large droplets and smaller particles and the transmission dynamics to allow for a replication competen and tinfection competent virus to establish an invasive infection in humans is complex. The size of the particles and the distance the particles may be expelled is variable and depends on many factors, including the size distribution of the particles, the propulsive force generated by the individual or the procedure, the relative humidity, evaporation level, settling velocity, direction and velocity of air flow, the number of air changes per hour, temperature, crowding and other environmental factors. In addition there is variability in the type of the respiratory virus in question, the dispersion, quantity, and distribution of the virus within the droplets and smaller particles, the stability of the virus, its replication and infection competence, ability to enter the respiratory tract, ability to bind to specific host cell receptors and to establish invasive infection in a susceptible host. The process is further complicated by debate regarding how well the use of quantitative polymerase chain reaction (PCR) techniques performed on respiratory specimens can be interpreted with respect to recovery of viable virus and its titer, depending on the timing of presentation and stage of illness [8-12]. Regardless of the uncertainties, one certainty is that the use of Personal Protective Equipment (PPE) including gloves, gowns, medical masks and eye protection in combination with patient placement in adequately ventilated single rooms represents one component of the Infection Prevention and Control (IPC) response to prevent transmission of pathogenic microorganisms to HCWs $[1,2]$. However the effectiveness of PPE depends on its availability, the proper physical environmental controls, adequate staff training, strict adherence to hand hygiene and appropriate human behaviour [13, 14].

\section{Modes of transmission of SARS-CoV-2}

Currently available evidence supports that the predominant route of human-to-human transmission of the SARS-CoV-2 is through respiratory droplets and/or contact routes [1, 15-19]. The report by the World Health Organization (WHO) Joint Mission on Coronavirus Disease 2019 (COVID-19) in China which analyzed the experience with 75,465 cases supports person-to-person droplet and fomite transmission during close unprotected contact, with the majority of SARS-CoV-2 transmission occurring within families in close contact with each other [16]. The vast majority $(78-85 \%)$ of the investigated infection clusters occurred within families, with a household secondary attack rate varying between 3 and $10 \%$, a finding that is not consistent with airborne transmission [16]. The reproduction number $\left(R_{0}\right)$ for the SARS-CoV-2 was estimated to be between 2.0-2.5, compatible with influenza and other respiratory viruses typical for a droplet/contact mode of transmission and very different than a classical airborne virus such as measles which is estimated to have a $R_{0}$ of greater than 10 and widely cited to be between 12 and 18 [16, 20]. Other detailed reports have also been consistent, finding a $R_{0}$ of 2.2-2.7 for SARS-CoV-2 [21, 22].

Multiple clinical and epidemiologic reports have now lent considerable support that the predominant route of human-to-human transmission of the SARS-CoV-2 is through respiratory droplets and/or contact routes and do not support significant airborne transmission. An investigation of 25 close contacts sitting within $2 \mathrm{~m}$ of a 
symptomatic index case with cough and a presymptomatic case, both confirmed to have COVID-19, multiple exposed flight crew members and potentially all 350 passengers on board an airplane during a 15-h flight revealed no evidence of transmission of SARS-CoV-2 [19] supporting a droplet as opposed to airborne transmission route. Although the cases were reported to be wearing masks on the flight, it is not possible to wear masks during eating and drinking and the filtration capacity of the mask would not likely have been adequate for the entire 15 hour flight. Another report in a clinical setting in which 41 health care workers (HCWs) were exposed for over $10 \mathrm{~min}$ and within $2 \mathrm{~m}$ of a patient with confirmed COVID-19 during an intense and difficult intubation and non-invasive ventilation scenario, involving multiple AGMPs, revealed no transmission events of SARS-CoV-2 with repetitive testing of all the HCWs [23]. The majority $(85 \%)$ of the HCWs were wearing a medical mask and other appropriate PPE while the remainder wore an N95 respirator. Another recent investigation of an initially undiagnosed COVID-19 patient with severe pneumonia with a confirmed high frequency of coughing and receiving oxygen therapy at $8 \mathrm{~L} / \mathrm{min}$ who was nursed in an open 10 bed cubicle of a general ward for $35 \mathrm{~h}$, with minimal spacing between patients, led to an exposure of 71 staff and 49 patients, including 7 staff and 10 patients who fulfilled the criteria of 'close contact' (within two metres of the index case for a $>15$ min or had performed AGMPs without a N95 respirator), identified no SARS-CoV-2 nosocomial transmission events [24]. All patients and 6/7 staff with close contact tested negative for COVID-19 despite inconsistent use of medical masks by the patients and either use of medical masks or N95 respirators by the HCWs. In total 76 tests were performed on 52 contacts of which all were negative, and all other identified contacts remained asymptomatic during the 28 day post-contact surveillance period [24]. The authors concluded that SARS-CoV-2 is not spread by the airborne route and that basic infection control measures, including the use of medical masks, hand and environmental hygiene are adequate to prevent nosocomial transmission of SARSCoV-2. Another recent study of 48 persons involved in a nosocomial outbreak of SARS-CoV-2 infections in the pediatric dialysis unit of the University Hospital of Münster found that after contact with the index case, 7 HCWs, 3 patients and one accompanying person became infected. All had either cumulative 15 min of faceto-face contact or were HCWs with exposure within a distance of $\leq 2 \mathrm{~m}$, which occurred without use of any PPE. Of the remaining contacts who had shared the same indoor environment without face-to-face contact or who had contact but at a distance of $>2 \mathrm{~m}$ but without any use of PPE, none were found to be positive for COVID-19 on testing [25]. Additional data supporting that airborne transmission is not a predominant mode of transmission and therefore that $\mathrm{N} 95$ respirators or their equivalent are not required for routine use is accruing from sites which use only medical masks as the component of PPE in the care of COVID-19 patients but have a well-trained and prepared staff complement. There have been an estimated 5544 person hours of continuous HCW exposure to 132 COVID-19 inpatients, using PPE consisting of gowns, gloves, medical masks, and face shields or goggles for routine care and the addition of a N95 respirator for any AGMPs within "designated" COVID-19 medical wards at 4 acute care hospitals in Calgary, Canada over the first 2 months of care delivery with no nosocomial SARS-CoV-2 transmission events documented in any HCWs to date [26].

Data from studies that sampled surfaces in the environment for the presence of SARS-CoV-2 RNA in the immediate airspace surrounding infected patients who had known significant viral loads in their respiratory secretions have provided both negative and positive results $[17,18,27-30]$. Several studies have now reported positive results for the presence of SARS-CoV-2 RNA in air samples but in extremely low copy numbers $/ \mathrm{m}^{3}$ or per liter of air sampled and would be highly unlikely to represent viable virus [28-30]. No studies to date have been able to find viable SARS-CoV-2 within air samples [30]. Even if viable virus were to be found in air samples, it would need to be demonstrated that SARS-CoV-2 in the samples was both replication and infection competent in the context of health care settings where PPE is being used appropriately in conjunction with diligent hand hygiene to consider that airborne transmission represents a significant mode of transmission.

A recent experimental laboratory study suggested that aerosol transmission of SARS-CoV-2 is plausible, because they demonstrated that the virus can remain viable in aerosols for $3 \mathrm{~h}$ based on their experimental design. However, they used a Collison 3-jet nebulizer to shear a large volume liquid suspension of a high viral inoculum to generate aerosolized viral particles which were then impacted against a hard surface inside a drum [31]. This mode of artificial mechanical aerosol production has been used for testing bioterrorism agents [32, 33] and has little relevance to a coughing patient with COVID19 in the clinical setting and does not offer evidence that the virus is routinely present in aerosols at the bedside. Another report suggested that based on laser light scattering observations, loud speech could emit oral droplet nuclei of about 4um in size that persist as a slowly descending cloud which remain airborne for more than 8 min and theoretically could contain viable virus capable of being inhaled into the lungs [34]. However this conjecture is dependent on the independent action 
hypothesis (IAH) and the authors readily admit that there is no evidence the IAH is valid for humans and SARS-CoV-2.Other reports have suggested that airborne transmission is a significant route of transmission for the SARS-CoV-2; the title of one report suggests that the world should face the reality that the virus is airborne [35-37]. These studies represent opinion pieces, one systematic review of mainly modelling plus some experimental studies, and brief case reports which do not utilize robust methods to rule out contact or fomite transmission or opportunistic airborne transmission.

A recent WHO report indicated that SARS-CoV-2 RNA has been detected in in feces in 30\% of cases within a few days of symptom onset and live virus was cultivated from stools in some cases [16]. This latter observation and our knowledge of the extensive transmission that has emerged in hundreds of outbreaks of norovirus on cruise ships raises the possibility of the fecal-oral route as an additional means of transmission for SARS-CoV-2 which deserves attention and further study [38-40]. A recent report from the Diamond Princess cruise ship reported that before disinfection, SARSCoV-2 RNA was identified on multiple surfaces up to 17 days after cabins were vacated from both symptomatic and asymptomatic infected passengers suggesting widespread contamination but likely no viable virus was present [41]. Similar extensive environmental contamination of surfaces by SARS-CoV-2 from infected patients has been reported [18]. Additional evidence is emerging about the recognition of contact as a major route of transmission with a recent report from China finding poor hand hygiene before and after contact with patients and improper PPE as significantly associated with $\mathrm{HCW}$ with poor hand hygiene being retained in the logistic regression with the highest relative risk [42].

\section{The choice of masks as a component of personal protective equipment for health care workers - what is the evidence?}

Guidance from the WHO states that "health care workers should wear a medical face mask (herein after termed medical mask) when entering a room where patients suspected or confirmed of being infected with SARS-CoV-2 are admitted and in any situation of care provided to a suspected or confirmed case". The use of a particulate respirator at least as protective as a US National Institute for Occupational Safety and Health (NIOSH)-certified N95, European Union (EU) standard FFP2, or equivalent, is recommended when performing aerosol-generating medical procedures $[1$, 2]. Some jurisdictions and professional societies have suggested that the precautionary principle [43] should be applied in the event of an outbreak of any new respiratory virus. In the context of the current
COVID-19 outbreak, several institutions initially issued guidance indicating that particulate respirators (designed to protect against $95 \%$ of airborne particulates when tested against a $0.3-\mu \mathrm{m}$ particles) should be used as a component of the PPE for the HCWs, rather than medical masks. Persisting with this approach and the subsequent differences in recommendations for the type of masks creates risk perception disparities for HCWs, which may be increased in jurisdictions in the world with limited or no access to particulate respirators, and in the event of domestic or global supply disruptions.

Strict adherence to the use of administrative controls and using medical masks as a component of PPE were shown to be effective with no reported transmission events to HCWs during the SARS outbreak in 2003 [44, 45 ] and in one setting without the use of airborne isolation rooms [45]. Although the appropriate use of fit tested particulate respirators as a component of PPE may be equally effective compared the use of medical masks for HCWs in the management of patients infected with coronavirus strains including SARS-CoV-2, it is important to note that there were multiple reports documenting SARS coronavirus transmission to HCWs despite the use of particulate respirators in conjunction with other PPE in accordance with guidelines which reflect failures to prevent transmission to HCWs using them [46-52]. The mechanisms of transmission in these latter settings are not well understood but draw attention to the points that the use of particulate respirators as a component of PPE do not provide infallible levels of protection to HCWs. It is likely that these failures relate to inappropriate use or self contamination events. Multiple studies using systems-based human factors analysis have demonstrated that lapses in adherence and active failures in the donning and doffing of PPE resulting in self-contamination, which may be the genesis of inoculation events leading to transmission of pathogens to HCWs [53, 54]. A review of the literature following the SARS outbreak in 2003 suggested that for PPE to be effective, its use should be as uncomplicated as possible and focus on key principles, strict adherence to protocols including those related to appropriate use of PPE, high compliance, and lend itself to achieve the highest level of effectiveness in preventing HCW transmission events $[55,56]$. These studies suggest there is a need to simplify the PPE processes to ensure that compliance may be achieved.

There were multiple reports of SARS among HCWs in hospital outbreaks reported from Canada, China, Hong Kong, Taiwan and Vietnam followed by MERS outbreaks with HCW transmission events in the Middle East and South Korea which were caused by a very similar coronavirus to the SARS-CoV-2. These hospital outbreaks serve to focus attention on the critical importance of 
IPC practices, including appropriate PPE use, and having adequate training and knowledge among $\mathrm{HCW}$ s to ensure that PPE, barrier precautions and hand hygiene practices are used appropriately $[1,2,14]$. The single most important concept identified in the management of patients affected by viruses transmitted by the droplet/contact route is the precision of execution in the use of PPE, and which should be the primary focus rather than on the type of mask used by HCWs as a component of PPE.

The findings from multiple systematic reviews and meta analyses over the last decade have not demonstrated any significant difference in the clinical effectiveness of particulate respirators compared to the use of medical masks when used by HCWs in multiple health care settings for the prevention of respiratory virus infections, including influenza [57-59]. A recent large well conducted cluster randomized multi-center, multi-year pragmatic effectiveness study study no evidence of greater clinical effectiveness of particulate respirators compared to medical masks in the prevention of acquisition of laboratory confirmed influenza in HCWs [60]. One of the systematic reviews commented about the harms of particulate respirators, especially when worn for prolonged periods [57]. Other studies have demonstrated side effects associated with the use of particulate respirators including facial dermatitis from the respirator components, increased work of breathing, respiratory fatigue, impaired work capacity, increased oxygen debt, early exhaustion at lighter workloads, elevated levels of $\mathrm{CO}_{2}$, increased nasal resistance, and increased noncompliance events leading to self-contamination (adjustments, respirator or face touches, under-the-respirator touches, and eye touches) [61-67]. These side effects are not encountered with the same frequency with the appropriate use of medical masks. An additional study has suggested pregnant women were not able to maintain their minute ventilation and had decreased oxygen uptake and increased carbon dioxide production even at rest [55]. The effects on the developing fetus are unknown. Studies of the use of particulate respirators in clinical settings have demonstrated anywhere between 44 and $97 \%$ of HCWs do not use the respirators properly [68].

\section{Conclusion}

Our view is that the weight of the scientific evidence to date indicates that particulate respirators offer no advantage over medical masks as a component of PPE for the prevention of respiratory viral infections transmitted by the droplet/contact route, when used for routine care in clinical settings. To date, the available evidence supports that the predominant route of transmission of SARS$\mathrm{CoV}-2$ is consistent with the droplet/contact route. There are potential unintended consequences of the use of particulate respirators that put HCWs at risk particularly with prolonged use, which have not been associated with the use of medical masks. HCWs should be apprised accordingly in an open and transparent manner regarding potential harms of particulate respirators in jurisdictions where particulate respirators are chosen for routine use as a component of PPE. In addition, particulate respirators are more costly, require fit testing, necessitate additional time and resources, do not provide an adequate fit in individuals with beards, and may provide a false sense of security. Moreover, in the current COVID-19 pandemic, shortages have been documented from overuse such that respirators were not available in settings where AGMPs are performed and where is evidence for their need. Regardless of whether jurisdictions choose the precautionary principle with consequent use of particulate respirators instead of medical masks as a component of PPE for routine care of COVID-19 patients, this choice must not detract from the critical importance of emphasizing that PPE is only one measure within a bundle that comprises administrative, environmental and engineering controls, as described in WHO's infection prevention and control of epidemic- and pandemic-prone acute respiratory infections in health care [2].

PPE used by HCWs caring for patients with COVID19 must be used with attention to detail and precision of execution which involves selecting the proper PPE and being trained in how to correctly don, doff and dispose of it - without self-contaminating oneself in the process, the latter underscoring the importance and attention required for hand hygiene. Additional evidence on the use of medical masks and respirators needs to be generated to help define and inform knowledge gaps as we learn more about the COVID-19 epidemic and HCW practices.

\section{Acknowledgements}

We are thankful to Nicole Lamont and Jenine Leal for reference checks and editing assistance.

\section{Authors' contributions \\ JC, WHS, DP, AH, MC, PRH contributed to the conception of this work. All authors were provided a draft of the manuscript for comments and were provided with an opportunity to present revisions. JC wrote the initial drafts of the manuscript and collated comments from the principal authors engaged in the conception of the work and later comments from all authors. All authors were provided a final version of the manuscript for approval.}

\section{Funding}

This Commentary was unfunded.

Availability of data and materials Not applicable.

Ethics approval and consent to participate Not applicable. 


\section{Consent for publication}

Not applicable.

\section{Competing interests}

The authors declare that they have no competing interests. The members of the WHO Infection Prevention and Control Research and Development Expert Group for COVID-19 who participated in the development of this manuscript, provide independent advice to WHO in their capacity as individuals with expertise in infection prevention and control.

\section{Author details}

'University of Calgary and Alberta Health Services, Calgary, Alberta, Canada. ${ }^{2}$ University of Hong Kong, Hong Kong, China. ${ }^{3}$ University of East Anglia, Norwich, UK. ${ }^{4}$ Hopitaux Universitaires de Genève, Geneva, Switzerland. ${ }^{5}$ Imperial College, London, United Kingdom. ${ }^{6}$ Colorado School of Public Health, Aurora, Colorado, USA.

Received: 4 June 2020 Accepted: 9 July 2020

Published online: 06 August 2020

\section{References}

1. World Health Organization. Coronavirus disease (COVID-19) technical guidance: Infection prevention and control. Geneva: World Health Organization; 2020. Available from: https://www.who.int/emergencies/diseases/novel-coronavirus-2 019/technical-guidance/infection-prevention-and-control.

2. World Health Organization. Infection prevention and control of epidemicand pandemic-prone acute respiratory infections in health care. Geneva: World Health Organization; 2014. Available from: https://apps.who.int/iris/ handle/10665/112656.

3. Hall CB. The spread of influenza and other respiratory viruses: complexities and conjectures. Clin Infect Dis. 2007;45(3):353-9.

4. Roy CJ, Milton DK. Airborne transmission of communicable infection--the elusive pathway. N Engl J Med. 2004;350(17):1710-2.

5. Brankston G, Gitterman L, Hirji Z, Lemieux C, Gardam M. Transmission of influenza a in human beings. Lancet Infect Dis. 2007;7(4):257-65.

6. Tellier R. Aerosol transmission of influenza a virus: a review of new studies. R Soc Interface. 2009;6(Suppl 6):S783-90.

7. Tellier R, Li Y, Cowling BJ, Tang JW. Recognition of aerosol transmission of infectious agents: a commentary. BMC Infect Dis. 2019;19(1):101.

8. Morawska L. Droplet fate in indoor environments, or can we prevent the spread of infection? Indoor Air. 2006;16(5):335-47.

9. Xie X, Li Y, Chwang AT, Ho PL, Seto WH. How far droplets can move in indoor environments-revisiting the Wells evaporation-falling curve. Indoor Air. 2007;17(3):211-25

10. Wei J, Li Y. Airborne spread of infectious agents in the indoor environment. Am J Infect Control. 2016;44(9 Suppl):S102-8.

11. Lindsley WG, Blachere FM, Thewlis RE, Vishnu A, Davis KA, Cao G, et al. Measurements of airborne influenza virus in aerosol particles from human coughs. PLoS One. 2010;5(11):e15100.

12. Brown JR, Tang JW, Pankhurst L, Klein N, Gant V, Lai KM, et al. Influenza virus survival in aerosols and estimates of viable virus loss resulting from aerosolization and air-sampling. J Hosp Infect. 2015;91(3):278-81.

13. Shaw K. The 2003 SARS outbreak and its impact on infection control practices. Public Health. 2006;120(1):8-14.

14. World Health Organization. Infection prevention and control during health care when novel coronavirus (nCoV) infection is suspected. Geneva: World Health Organization; 2020. Available from: https:/www.who.int/ publications-detail/infection-prevention-and-control-during-health-carewhen-novel-coronavirus-(ncov)-infection-is-suspected-20200125.

15. Chan JF, Yuan S, Kok KH, To KK, Chu H, Yang J, et al. A familial cluster of pneumonia associated with the 2019 novel coronavirus indicating personto-person transmission: a study of a family cluster. Lancet. 2020;395(10223): 514-23.

16. World Health Organization. Report of the WHO-China Joint Mission on Coronavirus Disease 2019 (COVID-19). Geneva: World Health Organization; 2020. p. 16-24. Available from: https:/www.who.int/publications/i/item/reportof-the-who-china-joint-mission-on-coronavirus-disease-2019-(covid-19).

17. Cheng VCC, Wong SC, Chen JHK, Yip CCY, Chuang VWM, Tsang OTY, et al, Escalating infection control response to the rapidly evolving epidemiology of the Coronavirus disease 2019 (COVID-19) due to SARS-CoV-2 in Hong Kong. Infect Control Hosp Epidemiol. 2020:1-24.
18. Ong SWX, Tan YK, Chia PY, Lee TH, Ng OT, Wong MSY, et al. Air, surface environmental, and personal protective equipment contamination by severe acute respiratory syndrome coronavirus 2 (SARS-CoV-2) from a symptomatic patient. Jama. 2020

19. Schwartz KL, Murti M, Finkelstein M, Leis J, Fitzgerald-Husek $A$, Bourns $L$, et al. Lack of COVID-19 transmission on an international flight2020 242020. Available from: https://www.cmaj.ca/content/192/7/E171/tab-e-letters\#lackof-covid-19-transmission-on-an-international-flight.

20. Guerra FM, Bolotin S, Lim G, Heffernan J, Deeks SL, Li Y, et al. The basic reproduction number (RO) of measles: a systematic review. Lancet Infect Dis. 2017:17(12):e420-e8.

21. Li Q, Guan X, Wu P, Wang X, Zhou L, Tong Y, et al. Early transmission dynamics in Wuhan, China, of novel coronavirus-infected pneumonia. N Engl J Med. 2020;382(13):1199-207.

22. Wu JT, Leung K, Leung GM. Nowcasting and forecasting the potential domestic and international spread of the 2019-nCoV outbreak originating in Wuhan, China: a modelling study. Lancet. 2020:395(10225):689-97.

23. Ng K, Poon BH, Kiat Puar TH, Shan Quah JL, Loh WJ, Wong YJ, et al. COVID19 and the risk to health care workers: a case report. Ann Intern Med. 2020; 172(11):766-767.

24. Wong SC, Kwong RT, Wu TC, Chan JWM, Chu MY, Lee SY, et al. Risk of nosocomial transmission of coronavirus disease 2019: an experience in a general ward setting in Hong Kong. J Hosp Infect. 2020;105(2):119-127.

25. Schwierzeck V, Konig JC, Kuhn J, Mellmann A, Correa-Martinez CL, Omran H, et al. First reported nosocomial outbreak of severe acute respiratory syndrome coronavirus 2 (SARS-CoV-2) in a pediatric dialysis unit. Clin Infect Dis. 2020;ciaa491. [published online ahead of print, 2020 Apr 27].

26. COVID-19 Scientific Advisory Group. COVID risk to healthcare workers. Alberta Health Services, Calgary, Alberta. May 4 2020. Available from: https:// www.albertahealthservices.ca/assets/info/ppih/if-ppih-covid-19-hcw-riskrapid-review.pdf.

27. Faridi S, Niazi S, Sadeghi K, Naddafi K, Yavarian J, Shamsipour M, et al. A field indoor air measurement of SARS-CoV-2 in the patient rooms of the largest hospital in Iran. Sci Total Environ. 2020;725:138401.

28. Liu Y, Ning Z, Chen Y, Guo M, Liu Y, Gali NK, et al. Aerodynamic analysis of SARS-CoV-2 in two Wuhan hospitals. Nature. 2020:582(7813):557-56.

29. Chia PY, Coleman KK, Tan YK, et al. Detection of air and surface contamination by SARS-CoV-2 in hospital rooms of infected patients. Nat Commun. 2020;11(1):2800

30. Santarpia JL, Rivera DN, Herrara V, Morwitzer MJ, Creager H, Santarpia GW, et al. Transmission potential of SARS-CoV-2 in viral shedding observed at the University of Nebraska Medical Center. medRxiv; 2020. https://doi.org/ $10.1101 / 2020.03 .23 .20039446$

31. van Doremalen N, Bushmaker T, Morris DH, Holbrook MG, Gamble A, Williamson BN, et al. Aerosol and surface stability of SARS-CoV-2 as compared with SARS-CoV-1. N Engl J Med. 2020;382:1564.

32. Committee on Animal Models for Testing Interventions Against Aerosolized Bioterrorism Agents. Overcoming challenges to develop countermeasures against aerosolized bioterrorism agents: appropriate use of animal models. In: (US) NRC. Washington, DC: National Academies Press (US); 2006.

33. May KR. The collision nebulizer: description, performance and application. J Aerosol Sci. 1973;4(3):235-43

34. Stadnytskyi V, Bax CE, Bax A, Anfinrud P. The airborne lifetime of small speech droplets and their potential importance in SARS-CoV-2 transmission. Proc Natl Acad Sci U S A. 2020;117(22):11875-7.

35. Morawska L, Cao J. Airborne transmission of SARS-CoV-2: the world should face the reality. Environ Int. 2020;139:105730.

36. Bahl P, Doolan C, de Silva C, Chughtai AA, Bourouiba L, Maclntyre CR. Airborne or droplet precautions for health workers treating COVID-19?. J Infect Dis. 2020;iiaa189. [published online ahead of print, 2020 Apr 16].

37. Lu J, Gu J, Li K, et al. COVID-19 Outbreak associated with air conditioning in restaurant, Guangzhou, China, 2020. Emerg Infect Dis. 2020;26(7):1628-1631.

38. Yeo C, Kaushal S, Yeo D. Enteric involvement of coronaviruses: is faecal-oral transmission of SARS-CoV-2 possible? Lancet Gastroenterol Hepatol. 2020; 5(4):335-7.

39. Freeland AL, Vaughan GH Jr, Banerjee SN. Acute gastroenteritis on cruise ships - United States, 2008-2014. MMWR Morb Mortal Wkly Rep. 2016;65(1):1-5.

40. Bert F, Scaioli G, Gualano MR, Passi S, Specchia ML, Cadeddu C, et al. Norovirus outbreaks on commercial cruise ships: a systematic review and new targets for the public health agenda. Food Environ Virol. 2014;6(2):67-74. 
41. Moriarty LF, Plucinski MM, Marston BJ, Kurbatova EV, Knust B, Murray EL, et al. Public health responses to COVID-19 outbreaks on cruise shipsworldwide, February-March 2020. MMWR Morb Mortal Wkly Rep:2020.

42. Ran L, Chen X, Wang Y, Wu W, Zhang L, Tan X. Risk Factors of Healthcare Workers with Corona Virus Disease 2019: A Retrospective Cohort Study in a Designated Hospital of Wuhan in China. Clin Infect Dis. 2020.

43. Martuzzi M, Tickner JA. editors. Chapter 3, The precautionary principle: a legal and policy history. Copenhagen: World Health Organization; 2004.

44. Seto WH, Tsang D, Yung RW, Ching TY, Ng TK, Ho M, et al. Effectiveness of precautions against droplets and contact in prevention of nosocomial transmission of severe acute respiratory syndrome (SARS). Lancet. 2003; 361(9368):1519-20.

45. Le DH, Bloom SA, Nguyen QH, Maloney SA, Le QM, Leitmeyer KC, et al. Lack of SARS transmission among public hospital workers, Vietnam. Emerg Infect Dis. 2004;10(2):265-8.

46. Liu JW, Lu SN, Chen SS, Yang KD, Lin MC, Wu CC, et al. Epidemiologic study and containment of a nosocomial outbreak of severe acute respiratory syndrome in a medical center in Kaohsiung, Taiwan. Infect Control Hosp Epidemiol. 2006;27(5):466-72.

47. Chen M, Leo YS, Ang B, Heng BH, Choo P. The outbreak of SARS at Tan tock Seng hospital--relating epidemiology to control. Ann Acad Med Singap. 2006;35(5):317-25.

48. Centers for Disease Control and Prevention. Cluster of severe acute respiratory syndrome cases among protected health-care workers - Toronto, Canada, April 2003. Washington, DC: Centers for Disease Control and Prevention; 2003. Available from: https://www.cdc.gov/mmwr/preview/ mmwrhtml/mm5219a1.htm.

49. Twu SJ, Chen TJ, Chen CJ, Olsen SJ, Lee LT, Fisk T, et al. Control measures for severe acute respiratory syndrome (SARS) in Taiwan. Emerg Infect Dis. 2003:9(6):718-20.

50. Ofner-Agostini M, Gravel D, McDonald LC, Lem M, Sarwal S, McGeer A, et al. Cluster of cases of severe acute respiratory syndrome among Toronto healthcare workers after implementation of infection control precautions: a case series. Infect Control Hosp Epidemiol. 2006;27(5):473-8.

51. Chen YC, Chen PJ, Chang SC, Kao CL, Wang SH, Wang LH, et al. Infection control and SARS transmission among healthcare workers, Taiwan. Emerg Infect Dis. 2004;10(5):895-8.

52. World Health Organization. SARS outbreak in the Philippines. Wkly Epidemiol Rec. 2003;78(22):189-92.

53. Krein SL, Mayer J, Harrod M, Weston LE, Gregory L, Petersen L, et al. Identification and characterization of failures in infectious agent transmission precaution practices in hospitals: a qualitative study. JAMA Intern Med. 2018;178(8):1016-57.

54. Mumma JM, Durso FT, Ferguson AN, Gipson CL, Casanova L, Erukunuakpor $K$, et al. Human factors risk analyses of a doffing protocol for Ebola-level personal protective equipment: mapping errors to contamination. Clin Infect Dis. 2018;66(6):950-8

55. Moore D, Gamage B, Bryce E, Copes R, Yassi A, Group BCIRPS. Protecting health care workers from SARS and other respiratory pathogens: organizational and individual factors that affect adherence to infection control guidelines. Am J Infect Control. 2005;33(2):88-96.

56. Yassi A, Moore D, Fitzgerald JM, Bigelow P, Hon CY, Bryce E, et al. Research gaps in protecting healthcare workers from SARS and other respiratory pathogens: an interdisciplinary, multi-stakeholder, evidence-based approach. J Occup Environ Med. 2005:47(1):41-50.

57. Jefferson T, Del Mar CB, Dooley L, Ferroni E, Al-Ansary LA, Bawazeer GA, et al. Physical interventions to interrupt or reduce the spread of respiratory viruses. Cochrane Database Syst Rev. 2011;7:CD006207.

58. Smith JD, MacDougall CC, Johnstone J, Copes RA, Schwartz B, Garber GE. Effectiveness of $\mathrm{N} 95$ respirators versus surgical masks in protecting health care workers from acute respiratory infection: a systematic review and meta-analysis. CMAJ. 2016;188(8):567-74.

59. Offeddu V, Yung CF, Low MSF, Tam CC. Effectiveness of masks and respirators against respiratory infections in healthcare workers: a systematic review and Meta-analysis. Clin Infect Dis. 2017;65(11):1934-42.

60. Radonovich LJ Jr, Simberkoff MS, Bessesen MT, Brown AC, Cummings DAT, Gaydos CA, et al. N95 respirators vs medical masks for preventing influenza among health care personnel: a randomized clinical trial. JAMA. 2019;322(9): 824-33
61. Foo CC, Goon AT, Leow YH, Goh CL. Adverse skin reactions to personal protective equipment against severe acute respiratory syndrome--a descriptive study in Singapore. Contact Dermatitis. 2006;55(5):291-4.

62. Tan KT, Greaves MW. N95 acne. Int J Dermatol. 2004;43(7):522-3.

63. Donovan J, Kudla I, Holness LD, Skotnicki-Grant S, Nethercott JR. Skin reactions following use of N95 facial masks. Dermatitis. 2007;18(2):104

64. Donovan J, Skotnicki-Grant S. Allergic contact dermatitis from formaldehyde textile resins in surgical uniforms and nonwoven textile masks. Dermatitis. 2007;18(1):40-4.

65. Zhu JH, Lee YJ, Wang DY, Lee H. Effects of long-duration wearing of N95 respirator and surgical facemask: a pilot study. J Lung Pulm Respir Res. 2014 1(4):97-100

66. Rebmann T, Carrico R, Wang J. Physiologic and other effects and compliance with long-term respirator use among medical intensive care unit nurses. Am J Infect Control. 2013;41(12):1218-23.

67. Tong PS, Kale AS, Ng K, Loke AP, Choolani MA, Lim CL, et al. Respiratory consequences of N95-type mask usage in pregnant healthcare workers-a controlled clinical study. Antimicrob Resist Infect Control. 2015;4:48.

68. Tokars Jl, McKinley GF, Otten J, Woodley C, Sordillo EM, Caldwell J, et al. Use and efficacy of tuberculosis infection control practices at hospitals with previous outbreaks of multidrug-resistant tuberculosis. Infect Control Hosp Epidemiol. 2001:22(7):449-55.

\section{Publisher's Note}

Springer Nature remains neutral with regard to jurisdictional claims in published maps and institutional affiliations.

\section{Ready to submit your research? Choose BMC and benefit from:}

- fast, convenient online submission

- thorough peer review by experienced researchers in your field

- rapid publication on acceptance

- support for research data, including large and complex data types

- gold Open Access which fosters wider collaboration and increased citations

- maximum visibility for your research: over $100 \mathrm{M}$ website views per year

At BMC, research is always in progress.

Learn more biomedcentral.com/submissions 